Journal of Investigative Psychology and Offender Profiling

J. Investig. Psych. Offender Profil. (2009)

Published online in Wiley InterScience (www.interscience.wiley.com). DOI: 10.1002/jip.100

\title{
Spatial and Environmental Consistency in Serial Sexual Assault
}

\author{
SAMANTHA LUNDRIGAN ${ }^{1, *}$, SARAH CZARNOMSKI ${ }^{2}$ and MARC WILSON ${ }^{3}$ \\ ${ }^{1}$ Institute of Criminology, University of Cambridge, Cambridge, UK \\ ${ }^{2}$ Camden Community Safety Partnership, UK \\ ${ }^{3}$ School of Psychology, Victoria University of Wellington, Wellington, New Zealand
}

\begin{abstract}
This study examines the crime patterns of 76 New Zealand serial sexual offenders in order to determine the extent to which offenders display locational consistency in their choice of crime locations. More specifically, the hypothesis was that there would be intraseries consistency in the distances travelled (spatial consistency) and the characteristics of the crime sites selected (environmental consistency) by serial sexual offenders.

For spatial consistency to be tested, the distances travelled from home to offend and the criminal range for each offence series were analysed. Support was found for spatial consistency, and, in line with much overseas research, it was also found that the offenders typically did not travel very far from home to offend (median distance of $3 \mathrm{~km}$ ).

The environmental consistency measure was made up of various physical, temporal, and contextual variables that described the environmental characteristics of an offence. As hypothesised, it was found that offenders displayed intraseries environmental consistency in offence site selection beyond the level of that expected by chance. The implications of this both for understanding offender spatial decision making and for geographical profiling are discussed. Copyright (C) 2009 John Wiley \& Sons, Ltd.
\end{abstract}

Key words: serial rape; spatial and environmental consistency; geographical profiling

\section{INTRODUCTION}

Past research shows that an offender's spatial decision making is influenced by four interrelated groups of factors: offender characteristics, offender knowledge/experience, target selection, and the environmental backcloth (Brantingham \& Brantingham, 1981). These factors influence the locational decisions offenders' make about both an area to search (spatial behaviour) and a microenvironment to exploit within that area (offence environment selection). Whilst there has been a considerable amount of research into the spatial

*Correspondence to: Samantha Lundrigan, Institute of Criminology, University of Cambridge, Sidgwick Avenue, Cambridge, CB3 9DT, UK.

E-mail: s1491@cam.ac.uk

Copyright (C) 2009 John Wiley \& Sons, Ltd. 


\section{S. Lundrigan et al.}

and environmental characteristics of individual offence locations (Miethe \& McCorkle, 1998), there is less research into the spatial behaviour and environmental choices of serial offenders. In particular, there has been little consideration of just how consistent such offenders are in their spatial and environmental decision making across their series of crimes.

In the past, the notion of offence consistency has typically been applied to behaviour at crime scenes rather than the locational elements of offences (Grubin, Kelly, \& Brunsdon, 2001). Furthermore, where locational consistency has been considered, it has been explored in relation to journey to crime distances only and has yet to encompass any broader elements of the environment in which an offence takes place. This study examines New Zealand serial sex offenders in order to determine the extent to which they are consistent across their series in both their spatial behaviour and offence environment selection.

\section{Spatial differentiation}

Studies of the spatial behaviour of serial sexual offenders have typically focused on two main areas. On the one hand, examination has been made of the average distances and range over which they operate (Le Beau, 1987b; Warren et al., 1998). On the other hand, attempts have been made to categorise them into different spatial groups such as marauders and commuters (Canter \& Larkin, 1993; Kocsis \& Irwin, 1997). A number of studies across different crime types and different cultural contexts have now found support for these two spatial groups. However, there has been little empirical examination of what might differentiate the two types of offenders, and the validity of this method of separation has rarely been tested.

Recently though, research has begun to focus on trying to determine if there are any measurable factors that differentiate these two types of offenders other than their spatial pattern. Meaney (2004) investigated the influence of demographic characteristics (age, gender, ethnicity), crime type (arson, rape, burglary), and environment type (rural or urban) on offender spatial patterns and found that the two groups could be differentiated on certain offender, offence, and environmental features. The proposal that explanations for different spatial patterns may lie partly in the environmental features of offending makes the assumption that such variables are stable or consistent enough across a series to be meaningfully utilised to distinguish between spatial patterns. However, to date, there has been little research into the extent or nature of serial offenders' consistency in offence site selection. Therefore, before examination can be made of the environmental factors that might distinguish between particular spatial groups, there is a need to establish to what extent and in what ways offenders are consistent in their environmental choices across their offending series. For example, if it were hypothesised that the particular type of land use (e.g. residential, commercial, industrial) targeted by an offender might contribute to whether he or she was a commuter or marauder, then it would first be necessary to establish that such targeting choices remain consistent across an offender's series before they could be used as an indicator of spatial pattern.

\section{Spatial and environmental consistency}

Canter (1995) describes that what he calls the 'offender consistency' hypothesis as 'the way an offender carries out a crime on one occasion will have some characteristic 
similarities to the way that he or she carries out crimes on other occasions' (p. 347). The assumption is that offenders are displaying characteristics that are typical of that offender and that the behaviours are not just random or determined entirely by the situation. Whilst limited support has been found for behavioural consistency in the crime scenes of serial rapists (Craik \& Patrick, 1994; Grubin et al., 2001), a more fruitful avenue of research has been into the notion of spatial consistency. Canter (2000) suggests that spatial consistency can be seen in serial offenders' behaviour in that they operate over 'limited environments'. Certainly, much support has been found for the local nature of offending, with offenders preferring familiar environments close to home than unfamiliar, distant ones (Amir, 1971; Rengert \& Wasilchick, 1985). Environments then can be seen as limited in that familiarity defines the extent of an offender's knowledge about potential opportunities and thus the parameters of his or her search range.

In the present study, the concept of spatial consistency is expanded to include more than just the distances travelled to offend. Here, two forms of interrelated consistency are considered. First is spatial consistency, which relates to the actual spatial behaviour an offender displays across a series, (i.e. the distances he or she travels to offend and the criminal range over which he or she operates). Second is environmental consistency. This relates to those features of the offence that relate to the environment and includes physical, contextual, and temporal elements of the offence.

As previously stated, there are four groups of factors that are thought to exert an influence on where sexual offences occur. With the exception of offender background characteristics, which remain stable over time, the environmental backcloth, target selection, and offender knowledge/experience describe dynamic features of either the offender or the environment. An offender's environmental and criminal knowledge and experience change as each offence is committed and as he or she goes about his non-offending, routine activities. Added to this, the dynamic nature of the environmental backcloth and the availability of suitable victims and suitable environments are never the same. Therefore, there is an open question as to how consistent offenders are, given this shifting backdrop. Given this, the following section discusses further the three dynamic groups of factors - offender knowledge, target selection, and the environmental backcloth—and how they might impact on consistency in offender spatial behaviour and offence environment selection.

\section{Offender knowledge/experience}

An offender's spatial decision making is closely tied to his own knowledge and experience of the environment. Suitable opportunities only become actual targets, and particular locations only become actual crime sites when filtered by the offender's knowledge and perceptions. In their model of offender search behaviour, Brantingham and Brantingham (1981) suggest that, as offenders go about their non-criminal, routine activities, they build up templates of the characteristics of 'good' victims, targets, and locations for criminal activity. They suggest that information flows are biased towards home and previously known areas. Offenders may feel more comfortable searching in certain places, often in familiar environments that have proved successful for committing offences in the past. What the offender has learnt and experienced may therefore lead to consistent use of the same type of offending environment, a similar distance from home.

Support for the influence of geographical knowledge and familiarity on spatial behaviour is found in the journey to crime literature, with offenders carrying out their criminal 


\section{S. Lundrigan et al.}

activities close to home. Davies and Dale (1995), e.g. found that one-third of the victims in their study of serial rape were approached within a mile of the offender's residence. Environmental familiarity then helps define the parameters within which an offender will search for targets to exploit. It might be expected that, once offenders located an area that they found suitable for criminal activity, they would then use it consistently. Yet, whilst there are examples of such offence behaviour, the risks involved in such a course of action are self-evident. It might therefore be expected that the offenders will maintain a familiar range from home but that their criminal activity will be distributed around that home. Support for the existence of characteristics ranges over which serial offenders operate has been found in research on serial murderers (Lundrigan \& Canter, 2001) and serial rapists (Canter \& Larkin, 1993). This research has illustrated that those offenders who tend to travel far from home for some types of crime also travel long distances for other types of crime, and the same relationship is true for offenders who travel shorter distances.

In relation to microenvironment selection, offenders may also be consistent in their locational choices. Based on their knowledge and experience, they may prefer to offend in specific locational settings that are familiar and therefore seemingly more predictable. Familiarity here has two possible interpretations. First, it can relate to knowledge of a location in terms of direct previous experience. For example, it is well known that many crime patterns are characterised by repeat victimisation where the same offender (or different offenders) victimise the same location/victim more than once (Pease, 1998). However, whilst this has been found to be a significant contributor to the incidence of property crime, the extent to which it occurs in stranger sexual offending is less clear. Second, familiarity can relate to a more indirect knowledge of a location because of a perceived familiarity with an area. Possibly, offenders prefer to target locations that bear environmental similarities (housing type, socio-economic status, etc.) to their own home environments, increasing the perceived comfort and familiarity despite no direct experience of the location concerned.

Brantingham and Brantingham (1981) suggest that, once an offender has learnt which cues are associated with good targets and locations, the template becomes 'relatively fixed and influences future search behaviour, thereby becoming self-reinforcing' (p 29). It would be expected, therefore, that such behaviour would translate into some level of consistency in offence environment selection.

\section{Target selection}

The type of victim an offender selects and his or her method of encountering that victim are environmental considerations that relate to modus operandi (MO). An offender's MO is the set of actions he or she typically employs to achieve the objective of the crime. Research in this area has shown that MO can be altered in response to negative experiences and/or new learning (Douglas \& Munn, 1992; Hazelwood \& Warren, 1990). For example, an offender who breaks into residential dwellings in the middle of the night to surprise a victim whilst the victim is sleeping may change from breaking windows to exploiting unlocked entry points after a potential victim was alerted by the sound of breaking glass and the offence had to be aborted.

A number of studies have focused on target characteristics of sexual offences. For example, Le Beau (1987a) reported on contextual methods of how the serial sexual offenders approached their victims. He found that breaking and entering was the most common method of approaching the victim (58\%), followed by kidnapping (23\%), and 
hitchhiking (7\%). However, there has been little examination of how consistent serial offenders are in their method of approach across a series. The way in which target considerations relate to consistency in spatial behaviour and environment selection can only be understood through a consideration of the environmental backcloth the offenders operate in.

\section{Environmental backcloth}

An offender's experience and target considerations must be realised against an environmental backcloth. Brantingham and Brantingham (1993) define the environmental backcloth as 'the uncountable elements that surround and are part of an individual and that may be influenced or influence his or her criminal behaviour' (p. 6). In the present study, it is those tangible features of the environment such as the type of area, its land use, socioeconomic characteristics, and temporal dynamics that are considered in relation to environmental consistency.

The notion of an environmental backcloth is closely related to the concept of opportunity. The backcloth is made up of dynamic and uncountable dimensions and features that provide potential opportunities for crime. Such opportunities are not uniformly distributed in space. An individual offender will interpret the backcloth according to his or her own needs, experiences, and background in order to find a suitable target in a suitable time and place. In terms of spatial behaviour, an offender may have to consistently travel to particular distances to locate particular types of victims. Similarly, in terms of environment selection, the offender may consistently victimise particular types of environments because they contain suitable victims. These environments may be similar in terms of land use, socio-economic status, and demographics.

There is also an important temporal dimension to consider in relation to the environmental backcloth. Different environments may offer more suitable opportunities at certain times during the day or days of the week, so offenders will select particular time frames within which to offend to maximise the availability of suitable victims. Furthermore, offenders may have responsibilities such as work and family life that impinge on the time they have to offend and so lead to consistent temporal patterns in offending behaviour.

It is clear that an offender's spatial decision making is characterised by a complex relationship between the offender, in terms of his knowledge, experience, and target needs and the environment, in terms of the availability of opportunities. Of course, it is important to note that total consistency would not be expected, as this would mean each crime was committed in the same location and in the same environment. Because an offence is the product of an interaction between a dynamic offender (in terms of experience and knowledge) and a dynamic environment (in terms of the opportunity backcloth), consistency will never be total.

The previous discussion about the consistency of serial offenders' spatial behaviour leads to two broad hypotheses:

1) That intraseries consistency will be found in the spatial behaviour of serial sexual offenders; and

2) That intraseries consistency will be found in the characteristics of the offence environments selected by serial sexual offenders.

The following section details the procedure and selection of variables used to examine these hypotheses. 


\section{METHOD}

\section{Data collection}

Information on both offenders and offences was collected from New Zealand Police files. Files were made available through the Criminal Profiling Squad, where copies of approximately 1,750 solved and unsolved single and serial sexual offence cases from across the country and from as far back as 1970 are held.

The Criminal Profiling Squad was set up in the late 1990s at the conclusion of a lengthy police investigation into Joseph Thompson, a prolific serial rapist whose 10-year offending career had terrorised the communities of South Auckland (for case details, see Corbett, 1996). Sexual crimes between strangers are difficult to investigate for two reasons: first, in identifying that a serial offender is in operation in the first place and, second, as there is no connection between the victim and the offender, actually locating the offender. Today, sophisticated databases that allow for the storage and searching of large quantities of information are used to assist in investigations of this type. However, at the time of the South Auckland rape enquiry, no such resource existed, so a national, centralised database of convicted, sexual offenders was introduced in order to aid in the linking and identification of future serial sexual offenders.

The process of centralising sexual offence information with the Profiling Squad began in 1999 with a nationwide request to police stations for copies of historical, stranger, sexual offence files. Whilst the majority of the cases sent involved strangers, there were also a number of acquaintance crimes included that had taken place within otherwise strangerperpetrated series. Since this initial request for historical cases, it is now common that, when a stranger assault by a stranger is committed anywhere in the country, a copy is sent to the profiling squad. However, it is not a mandatory requirement and relies on the motivation of the investigating officer in charge of the case. Therefore, whilst the files stored centrally represent a large proportion of reported sexual assaults by strangers, they do not include all such crimes. Another limitation of this type of secondary data collection is that the quality of the information and level of detail recorded within the files are variable. However, each file typically contains a summary of the offence, victim, and witness statements and details of all police enquiries. If an offender was convicted for the offence, then the trial summary of facts, along with information regarding his background characteristics and home address, is recorded. When a file is received, the Criminal Profiling Squad codes the crime scene and behavioural, background, and geographical information and enters it onto a searchable computer database.

\section{The sample}

For a case to be included in the present sample, a number of criteria had to be fulfilled. First, a case had to be part of an identified series of at least two offences. Second, the series had to have been solved and an offender convicted. Third, all offences in a series had to be sexual. Whilst the sexual behaviours ranged from indecent assault though to rape, in each series, at least one 'sexual violation' case had to have been committed for the offender and his offences to be included. In New Zealand, the legal definition of sexual violation includes penetration of any part of the offender's body or any object manipulated by the offender to the victim's vagina or anus. It also includes connection between the mouth or tongue of either the victim or offender and the genitalia of the other person. 
The application of these criteria resulted in a sample consisting of 76 offenders who had committed at least two sexual offences in New Zealand between the years 1970 and 2002. Collectively, the offenders were responsible for 270 offences, with the number of offences per series ranging from 2 to 14 (mean of 3.8, median of 3). Of the offenders, $34 \%$ had two known offences in their series, $28 \%$ had three offences, and $15 \%$ had four offences. The remaining $23 \%$ had between five and fourteen offences in their series. In terms to the relationship between the victim and the offender, the majority (79\%) of the offences were between strangers, $20 \%$ involved a friend or associate of the offender, and $1 \%$ involved a previous partner. The mean age of the offenders in the sample was 23 years $(\mathrm{SD}=7.96)$, with the youngest aged 12 years and the oldest aged 60 years. In terms of ethnicity, over half (53\%) of the offenders were recorded as being of Maori descent, and $21 \%$ of Pakeha (New Zealand European) descent. The remaining offenders included $18 \%$ Pacific Islanders, 3\% Asian, and 5\% unknown.

\section{Procedure}

Each offence in a series was coded onto a form that recorded information about the victim, offender, and offence. All addresses relating to the offender, victim, and offence were also recorded. The frequency with which the home address of the offender and the location of the offence were recorded in the original police files was high, as the police routinely record both. However, for six of the offence series, one offence address in each was found to be missing. Three of these offenders had series where more than one offence address was known and so were included in the sample. This was deemed acceptable, as when looking at an offence series (even if all the offence addresses are known), there is still a possibility that the offender has committed offences that are not known to the police. Therefore, as it is impossible to be sure of capturing a whole series of offences, knowing an offence took place and not being able to record it do not discount the rest of the series from inclusion in the sample. The remaining three offenders who had series where only one offence address was known were excluded.

For the geographical patterns of the sample to be examined, a computer mapping tool called Quickmap $($ was used. Quickmap is a geographical information system specifically developed for New Zealand by Custom Software Ltd. The program includes detailed street and topographical maps of New Zealand and allows distance measures between points both as real distance travelled (as the quickest road route from point to point) and 'crow's-flight' or straight line distance. Quickmap is available to businesses and the general public, (for more detailed information about this product, see www. quickmap.co.nz).

For this study, crow's-flight distance was used, as it makes no assumptions about the route taken from one point to another. There was no way of knowing the exact route taken by offenders when committing each of their crimes, and case files including witness and victim statements failed to shed any light on this. Crow's-flight distance also allows for comparison with other research of this kind because most North American and European studies utilise this measure.

For all distance measures used in the study, measurements were taken from the offence site rather than the victim-contact site. The rationale for this decision was the belief (of the authors) that the offence site is the most telling of the possible crime locations associated with an offence. The offender may have more choice over this location than the contact site, which is likely to be more dependent on victim location considerations. Where 


\section{S. Lundrigan et al.}

addresses were not specific enough to locate the exact offence site, e.g. a park, the midpoint of that area was used as the offence location.

\section{Consistency measures}

Spatial consistency manifests itself in the geographical connections of offenders crimes to their base and other offences. For this to be examined, a series of distance measures were calculated and are detailed in the results section.

Environmental consistency reveals itself in the characteristics of the offence environments an offender selects and includes physical, temporal, and contextual features of an offence. For environmental consistency to be tested, eight variables that described the environmental elements of an offence were identified. The selection of variables was guided by two considerations: first, their ability to describe an environmental feature of the offence and, second, the frequency with which such information was recorded in case files. Therefore, only variables that both described a feature of the offence environment and were frequently recorded in police files were included in the analysis. There are, of course, many other environmental variables that might have been included in this analysis. However, the choice of variables was limited to the availability of routinely recorded information and therefore does not reflect all the possible environmental features of an offence.

For the interrater reliability of the data coding to be estimated, Cohen's (1960) Kappa value was calculated for a random sample of $20 \%$ of the 76 series. An acceptable level of reliability was found, with Kappa values ranging from 0.65 (area type) to 0.85 (transportation). The resulting eight variables and their descriptions are listed in Table 1. One variable in particular requires further explanation. For the socio-economic level of offence areas to be determined, deprivation scores were obtained from the New Zealand Ministry of Health Deprivation Index. The index describes the deprivation experienced by people living in private accommodation for 21,201 small areas across New Zealand and is made up of nine variables that gauge relative deprivation (such as income level, unemployment, access to a car, educational attainment, and owner occupancy). The index ranges from 1 to 10 , with 10 being the most deprived and 1 being the least deprived (Crampton et al., 2000).

\section{RESULTS}

\section{Spatial consistency}

In order to get an indication of the mobility of the offenders in the sample, a number of simple spatial descriptive measures were carried out. As previously discussed, one of the most common measures of an offender's mobility is the journey-to-crime distance, which is simply a measurement of the crow's flight distance from the offenders homes to the site where they committed their offence (Rossmo, 2000). For the present sample, it was found that offenders travelled a mean of $17 \mathrm{~km}$ to offend. The median for the sample was much lower at $3 \mathrm{~km}$ and, as outliers can affect the mean, is more indicative of the average distance travelled. Distances travelled ranged from 0 to $485 \mathrm{~km}$, with $93 \%$ of the journey to crime distances within $60 \mathrm{~km}$ of home. Figure 1 illustrates the distribution of those journeys less than $60 \mathrm{~km}$. From this, it is evident that the majority of offences took place within close proximity of the offenders' homes. Indeed, $60 \%$ of the offences occurred within $5 \mathrm{~km}$ of home. 
Table 1. Consistency variables and their category descriptions

\begin{tabular}{|c|c|c|}
\hline Variable name & Description of variable & Categories \\
\hline Contact site & $\begin{array}{l}\text { Where the offender first encountered } \\
\text { the victim }\end{array}$ & $\begin{array}{l}\text { Victim's residence } \\
\text { Victim's work place } \\
\text { Shopping mall } \\
\text { Public street } \\
\text { Pub/Club } \\
\text { Park/Playground } \\
\text { Vehicle } \\
\text { Other }\end{array}$ \\
\hline Victim transportation & $\begin{array}{l}\text { Whether the offender transported the } \\
\text { victim during the commission of the } \\
\text { offence }\end{array}$ & $\begin{array}{l}\text { No transport } \\
\text { Transport from initial contact } \\
\text { to rape site } \\
\text { Transport from rape to } \\
\text { release site } \\
\text { Transport from initial contact } \\
\text { to rape to release site }\end{array}$ \\
\hline Day of week & The day of week the offence occurred & $\begin{array}{l}\text { Weekday (Mon-Thurs) } \\
\text { Weekend (Fri-Sun) }\end{array}$ \\
\hline Time of day & The time of day the offence occurred & $\begin{array}{l}\text { Morning }(0601-1200 \mathrm{~h}) \\
\text { Afternoon }(1201-1800 \mathrm{~h}) \\
\text { Evening }(1801-0000 \mathrm{~h}) \\
\text { Night }(0001-0600 \mathrm{~h})\end{array}$ \\
\hline Distance to offence & $\begin{array}{l}\text { Distance from offender home base to } \\
\text { offence location }\end{array}$ & $\begin{array}{l}0-5 \mathrm{~km} \\
5-10 \mathrm{~km} \\
10-15 \mathrm{~km} \\
15-20 \mathrm{~km} \\
>20 \mathrm{~km}\end{array}$ \\
\hline Area type & $\begin{array}{l}\text { The nature of the built environment } \\
\text { where the offence occurred }\end{array}$ & $\begin{array}{l}\text { Urban } \\
\text { Suburban } \\
\text { Rural }\end{array}$ \\
\hline Land use & $\begin{array}{l}\text { The dominant land use of the area } \\
\text { where the offence occurred }\end{array}$ & $\begin{array}{l}\text { Residential } \\
\text { Commercial } \\
\text { Industrial } \\
\text { Other }\end{array}$ \\
\hline Deprivation score & $\begin{array}{l}\text { The deprivation score of the area } \\
\text { where the offence occurred }\end{array}$ & $\begin{array}{l}\text { Scores range from } 1 \text { to } 10 \text {, } \\
\text { with } 10 \text { indicating the highest } \\
\text { level of deprivation and } 1 \text { the } \\
\text { lowest level }\end{array}$ \\
\hline
\end{tabular}

\section{Consistency correlation}

With the local nature of the offenders' spatial behaviour established, a more direct analysis of spatial consistency was carried out. This was a calculation of the correlation of maximum and minimum distances travelled to offend. It was hypothesised that, if offenders are consistent in their spatial behaviour, then those offenders who travel short minimum distances would also travel short maximum distances, and those offenders who travel large minimum distances also travel large maximum distances. Previous research by Lundrigan and Canter (2001) found support for this in their study of serial murderers. Indeed, there is no mathematical reason that minimum and maximum distances travelled to offend 


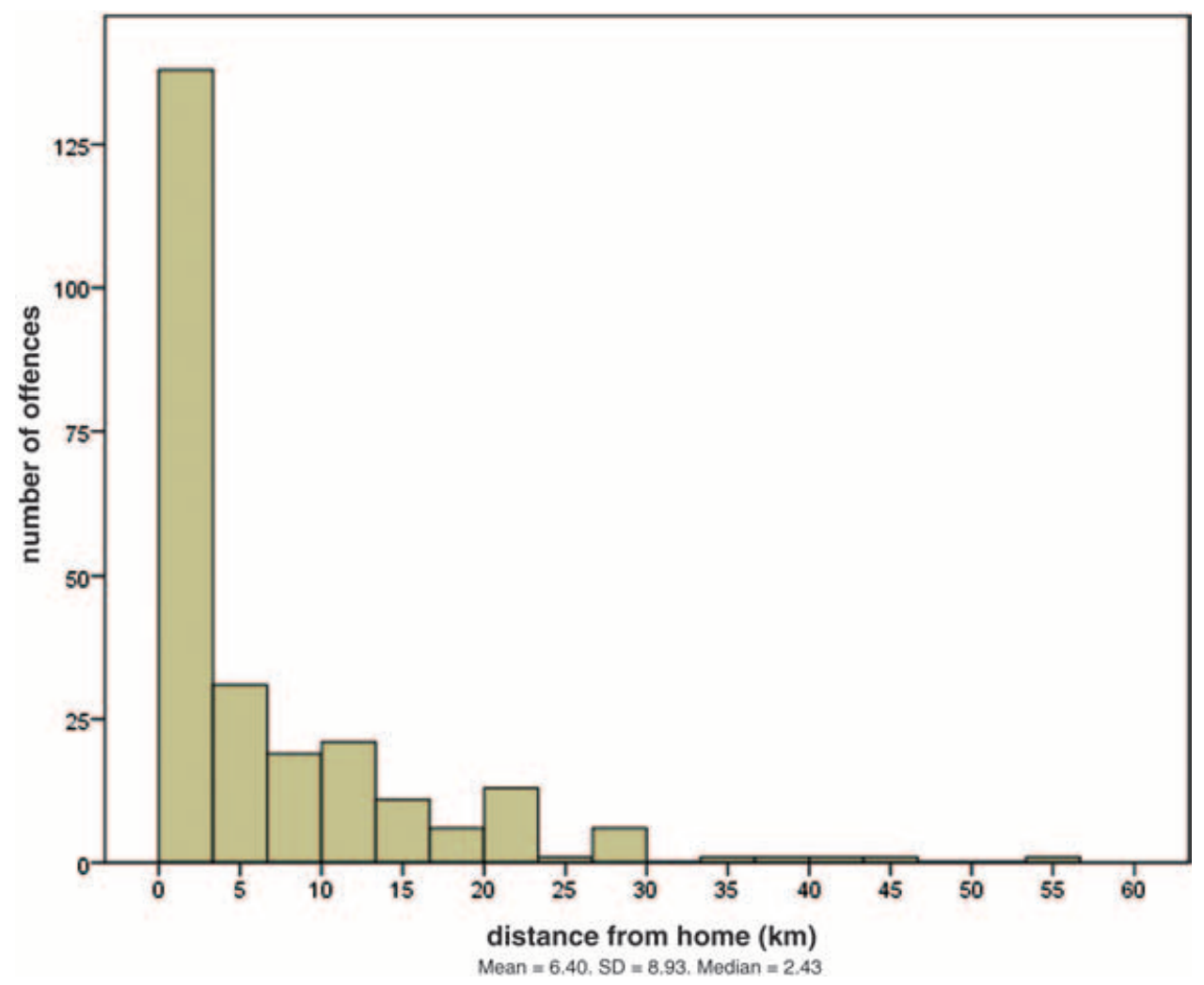

Figure 1. Frequency distribution of distances between base and crime site for 251 offence journeys $<60 \mathrm{~km}$ in length.

should be correlated. Therefore, if a positive correlation is found between the two, then it suggests that it is the result of the same processes affecting both distances. Results from the correlation of the two distances for the present sample showed a moderate positive correlation $(r=0.32, p<0.01)$. This finding suggests that offenders do display a level of consistency in terms of their spatial behaviour and are travelling characteristic distances to offend.

\section{Environmental consistency}

In order to examine whether intraseries environmental consistency was a feature of the offending behaviour of the sample, the eight variables listed in Table 1 were compared across each series. Consistency was measured by comparing each offence with the offence immediately before it for the full length of each offender's series. The procedure undertaken is detailed below.

1) Each variable was compared with its namesake in the previous offence and it was checked whether they both fell into the same category. If they both fell into the same category, a 1 was awarded; if they were in different categories, a 0 was awarded. Therefore for each offence-offence comparison there was a maximum possible consistency score of 8 (where all variable categories were the same), a minimum possible 
consistency score of 0 (where no variable categories were the same) and a 'scale' midpoint of 4.

2) An offender's overall mean consistency score was calculated by adding up all the comparison consistency scores then dividing the total by the number of comparisons made. For example, a series of five offences may have got the following consistency scores: $6,4,7$, and 5 . The total of the scores is 22 divided by the number of comparisons (which is 4) equals a mean consistency score of 5.5. Once again, these overall mean consistency scores ranged from 0 to 8 , with 0 being inconsistent and 8 being highly consistent.

Initial results from the consistency analysis (Table 2) show that none of the offenders are 'inconsistent', as defined by the consistency score. This can be seen by the minimum score, which is above zero. The average consistency score is beyond the midpoint of the overall consistency scores range of 4 .

Table 3 illustrates the frequency of occurrence of each consistency score. As can be seen, there are only a small number of offenders who score towards the low end of the consistency range, and over half of the offenders have scores greater than 4 .

In order to determine whether these results were statistically meaningful, they were compared to their proportional chance scores. Proportional chance scores measure the likelihood of getting any particular consistency score by chance (where 'chance' has been calculated to take into account the actual frequency of categories for each variable; Hair et al., 1998). As consistency scores now reflect the aggregated consistency over several variables, the proportional chance of a particular score now becomes a function not only of the proportional chance of receiving the same category for a single offence characteristic across two offences but also of the aggregated proportional chance across several characteristics.

Proportional chance values were calculated for all of the eight variables used in the consistency score (see Hair et al., 1998). The scores are shown in Table 4. For each one, the proportional chance represents the accuracy expected by randomly allocating catego-

Table 2. Descriptive statistics for consistency score calculations for 76 serial sexual offenders

\begin{tabular}{lc}
\hline Statistic & Score \\
\hline Mean & 4.56 \\
Median & 4.79 \\
Standard deviation & 1.70 \\
Minimum & 1.00 \\
Maximum & 8.00 \\
\hline
\end{tabular}

Table 3. Totals and cumulative percentages for offender consistency scores

\begin{tabular}{lcc}
\hline Consistency score & $n$ & Cumulative $\%$ \\
\hline $0 \leq 2$ & 8 & 10.5 \\
$2 \leq 4$ & 24 & 42.1 \\
$4 \leq 6$ & 31 & 82.9 \\
$6 \leq 8$ & 13 & 100.0 \\
\hline
\end{tabular}


Table 4. Proportional chance scores for the eight consistency variables

\begin{tabular}{lc}
\hline Variable & Proportional chance score \\
\hline Contact site & 0.32 \\
Transportation & 0.56 \\
Day of week & 0.50 \\
Time of day & 0.30 \\
Area type & 0.53 \\
Land type & 0.59 \\
Deprivation score & 0.12 \\
Distance to offence & 0.38 \\
\hline
\end{tabular}

Table 5. The proportional chance of scoring in the same category as a previous offence for varying numbers of variables

\begin{tabular}{lcc}
\hline $\begin{array}{l}\text { Number of variables } \\
\text { the same as } \\
\text { previous offence }\end{array}$ & $\begin{array}{c}\text { Average chance } \\
\text { of occurring } \\
\text { (decimal) }\end{array}$ & $\begin{array}{c}\text { Average } \\
\text { chance of } \\
\text { occurring (\%) }\end{array}$ \\
\hline 8 & 0.0004 & $<1$ \\
7 & 0.0012 & $<1$ \\
6 & 0.0035 & $<1$ \\
5 & 0.0096 & $<1$ \\
4 & 0.0253 & 2 \\
3 & 0.0661 & 7 \\
2 & 0.1670 & 17 \\
1 & 0.4126 & 41 \\
\hline
\end{tabular}

ries; for example, we would expect similarity between offences on transportation $56 \%$ of the time simply because some categories are more frequent than others.

The proportional chance of finding consistency on only one (and inconsistency on seven) of the eight variables is the sum of proportional chances shown in Table 4, divided by the number of variables, or $41 \%$, and this figure declines for each additional consistent variable. In order for an offender to have one offence completely consistent to its previous offence, all eight variables must be the same. The chance of high consistency (all eight variables the same) is calculated by multiplying the proportional chance scores of all eight variables together. Therefore, the chance of getting high consistency (all eight consistent) is 0.0004 , which is less than $1 \%$. Table 5 shows the likelihood of the average chance of getting any number of the eight variables the same as the previous offence.

Superficially then, the present sample appears to exhibit a degree of consistency beyond the level of chance. Whilst not all offenders were highly consistent, just under half of the offenders were consistent $50 \%$ or more of the time. A significance test again suggests that the number of offenders scoring above 4 (the consistency 'scale' midpoint, and just below the observed median), 44 offenders ( $57 \%$ of the sample), is statistically greater than the $2.5 \%$ proportional chance expected $(z=45.42, p<0.0001)$. Even if the offenders scoring 4 or more do so because they show consistency on the variables with the greatest proportional chance associated with them (land type: $59 \%$; transportation: $56 \%$; area type: $53 \%$; and day of week: $50 \%$, with a combined proportional chance of $8.7 \%$ ), the observed $57 \%$ (score of 4 or more) is still statistically significant $(z=22.45, p<0.001)$. This indicates 
Table 6. Frequency of consistency scores when comparing a random offence with another of the same offender's offences, and with that of a random-other offender

\begin{tabular}{lcc}
\hline $\begin{array}{l}\text { Number of } \\
\text { variables consistent }\end{array}$ & $\begin{array}{c}\text { With own } \\
\text { offence (SD) }\end{array}$ & $\begin{array}{c}\text { With random- } \\
\text { other offence (SD) }\end{array}$ \\
\hline 0 & $3(3.9)$ & $3(3.9)$ \\
1 & $4(5.3)$ & $10(13.2)$ \\
2 & $8(10.5)$ & $12(15.8)$ \\
3 & $9(11.8)$ & $15(19.7)$ \\
4 & $13(17.1)$ & $16(21.1)$ \\
5 & $17(22.4)$ & $12(15.8)$ \\
6 & $7(9.2)$ & $6(7.9)$ \\
7 & $12(15.8)$ & $1(1.3)$ \\
8 & $3(3.9)$ & $1(1.3)$ \\
Mean & $4.39(2.05)$ & $3.34(1.75)$ \\
\hline
\end{tabular}

that the levels of consistency gained by this sample are occurring at a greater-than-chance level.

\section{Interoffender consistency comparison}

In a further attempt to determine the level of relative consistency, consistency scores were computed first for each of the 76 offenders, based on two of their own offences and between one of their own and one other offence selected at random from those of other offenders. If offenders are consistent to any degree in the characteristics of their own offences, then we would expect there to be greater consistency within their own offences than with those of other offenders. Table 6 shows the distribution of frequencies (and percentages $)$ of consistency scores $(0=$ no consistency on any of the eight variables, $8=$ all consistent). There is a trend for consistency scores to be higher when comparing within offenders than when comparing between. Indeed, consistency with one's own offences is significantly greater than when comparing one's own and a random other offence. $(\mathrm{F}[1,75]=19.86, p<0.001)$. In conjunction with results already presented, this indicates that not only do offenders tend to show consistency greater than expected by chance (when taking into account the a priori frequency of particular offence attributes) but they also are more consistent with their own offences than with those of other offenders.

\section{DISCUSSION}

This study has sought to examine the extent and nature of spatial and environmental consistency in the offending behaviour of serial sexual offenders. In relation to spatial consistency, it was hypothesised that offenders would travel consistent distances to offend across their series. Support for this was found in the journey to crime of the offenders, with a significant correlation between minimum and maximum distance travelled to offend. In other words, those offenders who were travelling short minimum distances to offend were also travelling short maximum distances to offend and vice versa. This suggests that offenders are not selecting random locations to travel to for their offending. Rather, whilst never identical, the distances travelled across a series appear to reflect a characteristics range of operation for the offender. Such characteristics ranges are likely to be indicative 


\section{S. Lundrigan et al.}

of an offender's own knowledge and experience of the environment. The suggestion that the distances an offender travels to offend are not based on a random exploration for suitable victims is by no means new, and explanations for this well-established finding focus on the influence of spatial familiarity (typically set by the parameters of routine, day-to-day activity spaces) as well as the balance between perceived risk, effort, and opportunity.

In relation to environmental consistency, it was hypothesised that offenders would select similar offence circumstances and environments to offend in across their series. The results of an examination of the intraseries characteristics of a number of environmental variables indicated that, whilst not all offenders were highly consistent, just under half were consistent $50 \%$ or more of the time.

Interpreting these results in isolation, however, was difficult, as there was no obvious cut-off point above which an individual can be considered consistent and below which they can be considered inconsistent. Therefore, in order to test whether the results were meaningful, the offenders' consistency scores were compared with their scores as predicted by chance. The resulting analysis clearly indicated that the levels of consistency gained by this sample were occurring at a greater-than-chance level. Further support for environmental consistency was found when an offender's own offences were compared with those of other offenders. This revealed that offenders were significantly more consistent with their own offences than with those of randomly selected offenders. Interestingly, though, it was not possible to identify any variables that were particularly consistent, as those variables that had the highest consistency scores also had the highest proportional chance scores. Instead, it was a combination of variables that was contributing to the overall consistency for these offenders.

The finding that offenders are displaying measurable levels of consistency in their environmental choices across their series is an important one that needs further discussion and research. In particular, there is a need to establish more clearly which environmental characteristics are the most consistent and the least susceptible to change. Whilst some characteristics would be hypothesised to be more resistant to change, it must be remembered that offenders do not remain static in a dynamic environment. They can develop and change their behaviour in response to situational factors, previous experience, learning, and changes in circumstance. MO is certainly open to change in these ways. Those features of an offender's MO that relate to the environment include offence timing, victim encounter location, and victim transportation and may be less susceptible to change than more direct aspects of the offence environment.

The environment within which an offence takes place can be described in a number of ways. In the present study, information on the type of area (rural, urban, suburban), land use (residential, commercial, etc.), and deprivation level was available. How consistent offenders are in terms of the characteristics of the environments they select is likely to relate to their target choice on the one hand and to the environmental homogeneity of their search area on the other. As long as offenders are consistent in their target type and do not relocate to an area with very different dominant characteristics, then a reasonably high level of consistency could be expected.

Overall, regardless of the relative consistency of each individual characteristic, the combined consistency levels found in the present study suggest that offenders are not selecting environments randomly but that whatever might be influencing the selection of one environment is also influencing the selection of subsequent environments. The implications of such consistency are discussed below. 
Canter (2000) suggests that 'a number of researchers have demonstrated the practical utility of models of offender spatial consistency'. He is referring to the developments over recent years in the applied area of geographical profiling. This method of offender residence prediction relies on the consistency of offender spatial behaviour in order to predict where an offender might live, based on an analysis of his crime locations. This study has examined the intraseries consistency of serial sex offenders. The notion of consistency can also be extended to include the characteristics of an offender's home environment. In other words, there is an open question as to the level of concurrence between the characteristics of offenders' home environments and the offence environments that they select to offend in. The explanations that focus on familiarity and comfort as key attributes of suitable offence environments would certainly suggest that there might be some similarities between the two. Any evidence in support of the notion of offender-offence consistency has obvious implications for geographical profiling.

This study relied on police-generated information for its data collection. This presented two main limitations that need to be acknowledged. First, the information was originally collected for a purpose other than this research. This meant that it was not possible to collect information on all possible environmental variables other than those that had just been originally recorded. This was particularly true of information relating to victim characteristics that were limited at best and completely absent at worst. Therefore, this study could not provide a complete analysis of the environmental variables relevant to serial sexual offenders, rather, only an analysis of those that were available in the police files.

Second, the information is only representative of that group of offenders who have been processed through the criminal justice system. Furthermore, the majority of offences stored by the Profiling Squad took place in Auckland, New Zealand's largest city. Whilst there is no doubt that the city does have a very high sexual offence rate compared with many other areas, it is likely that crimes from this location are overrepresented in the sample. However, the data collection phase of this study is a rolling one, with more offenders being added to the sample as they become known about. Therefore, it is hoped that the analysis will be continuously updated and broadened.

The location where a crime occurs is one of the least ambiguous elements of an offence. Offenders do not select locations and environments in which to offend randomly. Instead, the spatial behaviour and offence environment selection of offenders are influenced by the knowledge, experience, and target needs of the offender. However, this is only half the equation. For an offence to occur, the experience, knowledge, and needs of the offender have to be translated in a complex, dynamic environment. Despite the evolving nature of the environment, it has been possible to demonstrate that offenders are relatively consistent in their spatial choices across their series. This lends further support to the notion that the spatial patterns left by serial offenders can be used to reveal something about them and their understanding of the environment in which they operate.

\section{ACKNOWLEDGEMENTS}

The authors extend their thanks to New Zealand Police Criminal Profiling Squad and New Zealand Police National Headquarters for providing us with access to the data used in this study. The authors would also like to thank two anonymous reviewers for their helpful comments on the paper. 


\section{REFERENCES}

Amir, M. (1971). Patterns in forcible rape. Chicago: University of Chicago Press.

Brantingham, P. J., \& Brantingham, P. L. (1981). Environmental criminology. Beverley Hills: Sage Publications.

Brantingham, P. L., \& Brantingham, P. J. (1993). Nodes, paths and edges: Considerations on the complexity of crime and the physical environment. Journal of Environmental Psychology, 13, $3-28$.

Canter, D., \& Larkin, P. (1993). The environmental range of serial rapists. Journal of Environmental Psychology, 13, 63-69.

Canter, D. (1995). Psychology of offender profiling. In R. Bull, \& D. Carson (Eds.), Handbook of Psychology in Legal Contexts (pp. 343-355). Chichester, West Sussex: John Wiley \& Sons.

Canter, D. (2000). Offender profiling and criminal differentiation. Legal and Criminological Psychology, 5, 23-46.

Cohen, J. (1960). A coefficient of agreement for nominal scales. Educational and Psychological Measurement, 20, 37-46.

Corbett, J. (1996). Caught by his past. Auckland: Tandem Press.

Craik, M., \& Patrick, A. (1994). Linking serial offences. Policing, 10, 181-187.

Crampton, P., Salmond, C., Kirkpatrick, R., Scarborough, R., \& Skelly, C. (2000). Degrees of deprivation in New Zealand: An atlas of socioeconomic difference. Auckland: David Bateman.

Douglas, J. E., \& Munn, C. (1992). Violent crime scene analysis: Modus operandi, signature and staging. FBI Law Enforcement Bulletin, 61, 1-10.

Davies, A., \& Dale, A. (1995). Locating the stranger rapist. Home Office Police Research Group. Special Interest Series, Paper 3. London: HMSO.

Grubin, D., Kelly, P., \& Brunsdon, C. (2001). Linking serious sexual assaults through behaviour. Home office research study 215. Home Office Research Development and Statistics Directorate.

Hair, J. F., Anderson, R. E., Tatham, R. L., \& Black, W. C. (1998). Multivariate data analysis (5th ed.). Englewood Cliffs, NJ: Prentice Hall.

Hazelwood, R., \& Warren, J. (1990). The criminal behaviour of the serial rapist. FBI Law Enforcement Bulletin, February, 11-17.

Le Beau, J. L. (1987a). The journey to rape: Geographic distance and the rapist's method of approaching the victim. Journal of Police Science and Administration, 15, 129-161.

Le Beau, J. L. (1987b). The methods and measures of centrography and the spatial dynamics of rape. Journal of Quantitative Criminology, 3, 125-141.

Kocsis, R. N., \& Irwin, H. J. (1997). An analysis of spatial patterns in serial rape, arson and burglary: The utility of the circle theory of environmental range for psychological profiling. Psychiatry, Psychology and Law, 4, 195-206.

Lundrigan, S., \& Canter, D. (2001). A multivariate analysis of serial murderers' disposal site location choice. Journal of Environmental Psychology, 21, 423-432

Meaney, R. (2004). Commuters and marauders: An examination of the spatial behaviour of serial criminals. Journal of Investigative Psychology and Offender Profiling, 1, 121-137.

Miethe, T. D., \& McCorkle, R. (1998). Crime profiles: The anatomy of dangerous persons, places and situations. Los Angeles, CA: Roxbury Publishing Company.

Pease, K. (1998). Repeat victimisation: Taking stock. Crime detection and prevention series paper 90. London: Home Office Police Research Group.

Rengert, G. F., \& Wasilchick, J. (1985). Suburban burglary: A time and a place for everything. Springfield, IL: Charles C. Thomas.

Rossmo, D. K. (2000). Geographic profiling. Boca Raton, FL: CRC Press.

Warren, J. L., Reboussin, R., Hazelwood, R. R., Cummings, A., Gibbs, N., \& Trumbetta, S. (1998). Crime scene and distance correlates of serial rape. Journal of Quantitative Criminology, 14, $35-59$. 